\title{
A MAXIMUM ENTROPY MODEL OF THE BEARDED CAPUCHIN MONKEY HABITAT INCORPORATING TOPOGRAPHY AND SPECTRAL UNMIXING ANALYSIS
}

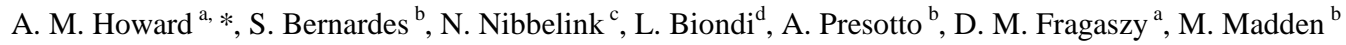 \\ a Dept. of Psychology, University of Georgia (UGA), Athens, GA, United States - (aeury, doree)@uga.edu \\ ${ }^{\mathrm{b}}$ Dept. of Geography, UGA, Athens, GA, United States - (sbernard, apresotto, mmadden)@uga.edu \\ ${ }^{\mathrm{c}}$ Warnell School of Forestry and Natural Resources, UGA, Athens, GA, United States - nate@warnell.uga.edu \\ ${ }^{\mathrm{d}}$ Psicologia Experimental, University of São Paulo, São Paulo, Brazil - biondi.luiz@ gmail.com
}

Commission II, WG II/1

KEY WORDS: Analysis, Ecology, Landsat, Landscape, Modelling,

\begin{abstract}
:
Movement patterns of bearded capuchin monkeys (Cebus (Sapajus) libidinosus) in northeastern Brazil are likely impacted by environmental features such as elevation, vegetation density, or vegetation type. Habitat preferences of these monkeys provide insights regarding the impact of environmental features on species ecology and the degree to which they incorporate these features in movement decisions. In order to evaluate environmental features influencing movement patterns and predict areas suitable for movement, we employed a maximum entropy modelling approach, using observation points along capuchin monkey daily routes as species presence points. We combined these presence points with spatial data on important environmental features from remotely sensed data on land cover and topography. A spectral mixing analysis procedure was used to generate fraction images that represent green vegetation, shade and soil of the study area. A Landsat Thematic Mapper scene of the area of study was geometrically and atmospherically corrected and used as input in a Minimum Noise Fraction (MNF) procedure and a linear spectral unmixing approach was used to generate the fraction images. These fraction images and elevation were the environmental layer inputs for our logistic MaxEnt model of capuchin movement. Our models' predictive power (test AUC) was 0.775 . Areas of high elevation (>450 m) showed low probabilities of presence, and percent green vegetation was the greatest overall contributor to model AUC. This work has implications for predicting daily movement patterns of capuchins in our field site, as suitability values from our model may relate to habitat preference and facility of movement.
\end{abstract}

\section{INTRODUCTION}

\subsection{Animal Movement and Environmental Features}

Since most animals must move from their present location to reach distant resources, bedding sites, or mates, the manner in which they choose routes and recall the locations of goal sites is a subject of considerable interest (e.g., Garber, 1989; Getz \& Saltz, 2008; Loureiro et al., 2007). Identifying the preferred habitat types for a variety of behaviors (e.g., movement, foraging, mating) gives us important information on the behavioural ecology of animals and may enhance conservation efforts for that species. It is likely that animal movement patterns and their habitat preferences are related to environmental features. Some primate species are known to use travel paths that correspond with salient topographical characteristics. For example, sympatric spider monkeys (Ateles belzebuth) and woolly monkeys (Lagothrix poeppigii) follow ridgelines in their repeatedly used paths (Di Fiore \& Suarez, 2007). This use of topographic features in the movement patterns of these animals may reduce the cognitive load of recalling the location of all preferred resource sites and may also maximize visual access to all potential resource sites while serving as important landmarks in the navigation of these animals. In addition to topography, land cover likely influences animal movement decisions as well. For example, Eleodes spp. beetle movements are characterized by high net displacement in areas of bare soil and lower net displacement in areas of shrub vegetation (Crist et al., 1992).

\footnotetext{
* Corresponding author
}

\subsection{Quantifying Environmental Variables}

A challenge of studying animal movement and associating movement with environmental variables is the identification and quantification of relevant landscape variables over space and time. The use of remotely sensed imagery has empowered researchers in multiple fields, with particularly significant contributions to landscape characterization in animal ecology studies (e.g., Stickler \& Southworth, 2008; Willems et al., 2009). Despite its great potential, the use of remotely sensed data to study fine-scale animal movement patterns has been limited. When used in this field, products derived from remote sensing are usually restricted to hard classifications of land cover or to the analysis of vegetation indices, such as the Normalized Difference Vegetation Index (NDVI). These products often provide an incomplete depiction of the landscape, limiting our ability to adequately represent the fuzziness and natural gradations of most environments (Elmore et al., 2000; Gao et al., 2000; Small, 2004). Spectral Mixing Analysis, a well-tested remote sensing technique, provides a representation of areal coverage and gradients of chosen key primary landscape descriptors, often vegetation, soil and shade. When compared to hard classifications and vegetation indices, products derived from spectral mixing analysis provide a more complete and accurate representation of complex landscapes (Small, 2004). 


\subsection{A Maximum Entropy Approach to Modelling Movement}

Many mathematical modelling tools have been developed to link observed species presence points with environmental variables for the purpose of creating a species distribution model (SDM) from occurrence data (e.g., BioClim, DOMAIN, GARP). These tools estimate geographic distributions for a given species based upon areas of similar environmental composition to the input observation points.

MaxEnt, a software package developed for modelling species distributions using environmental layers, species presence points, and background points (Phillips et al., 2006), performs well when compared with other SDM techniques (Elith et al., 2011). MaxEnt creates a continuous species distribution map where the value of each pixel of the modelled area represents a probability of presence of the study species in that pixel.

Generally, SDMs are developed for relatively large geographic areas, and the resultant areal distribution is used in predictions of where a species may have its range (Elith \& Leathwick, 2009). Species presence data used for the development of these models is frequently collected using systematic surveys (e.g., Fleishman et al., 2001) or from relatively sparse location acquisitions of radio-collared animals (e.g., Wirsing et al., 2002). However, in modelling species movement over much finer spatial and temporal scales, we believe that a similar technique can be applied effectively to represent the habitat characteristics animals prefer for movement. The data collected for this type of modelling must be representative of animal movements over fine scale space, and therefore requires following the study animal and acquiring geographic coordinates of their routes at frequent time intervals.

We characterize the habitat preferences for the movements of bearded capuchin monkeys (Cebus (Sapajus) libidinosus) based on the environmental features of the habitat in which they move. The habitat of capuchin monkey movement is quantified through the use of a spectral mixing analysis of land cover in conjunction with a digital elevation model (DEM) of the study area. These environmental layers serve as inputs to the MaxEnt model of capuchin movement within our study site in northeastern Brazil.

\section{METHOD}

\subsection{Study Site and Subjects}

We studied bearded capuchin monkeys (Cebus (Sapajus) libidinosus) at our research site (hereafter, Boa Vista) in the state of Piauí, in northeastern Brazil (centered at $9^{\circ} 39^{\prime} \mathrm{S}, 45^{\circ}$ $\left.26^{\prime} \mathrm{W}\right)$. The site encompasses the home range of several capuchin groups and is physiographically characterized by a highly weathered landscape where ridges and mesas, resulting from differential erosion, are notable geomorphological features. The climate of the region is seasonally dry, with lowest precipitation values recorded from April to September. On average, the region receives $1,112 \mathrm{~mm}$ of precipitation annually, with dry season precipitation totaling $203 \mathrm{~mm}$ (data source: Brazilian National Water Agency-ANA). Bearded capuchins are generalized quadrupedal New World primates living in a savanna habitat that spend over $30 \%$ of their time on the ground (Biondi, 2010) and are frequently studied for their unique use of stone tools to crack nuts for food (Fragaszy et al, 2004).

\subsection{Field Data Collection}

In Boa Vista, route data were collected for two groups of bearded capuchin monkeys with overlapping home ranges for a total of approximately 10 days per month (between both groups) from October 2008 to September 2009 (except May 2009). During route data collection, an observer followed the group staying within 20 meters of the group center and collected GPS coordinates for the location of the monkey group at five-minute intervals. When the center of the group was greater than 20 meters from the observer, the approximate distance and compass direction of the group center from the observer was recorded manually. Group follows were conducted from approximately 7 am to $5 \mathrm{pm}$ each day of data collection. These route coordinates $(6,973$ total points) were entered into a GIS (ArcGIS 10), and the distance corrections for the point estimates were edited using right angle trigonometry.

\subsection{Environmental Layers and Spectral Mixing Analysis}

Environmental layer inputs to the MaxEnt model of bearded capuchin monkey movement included elevation, percent exposed soil, percent green vegetation, and percent shade. For
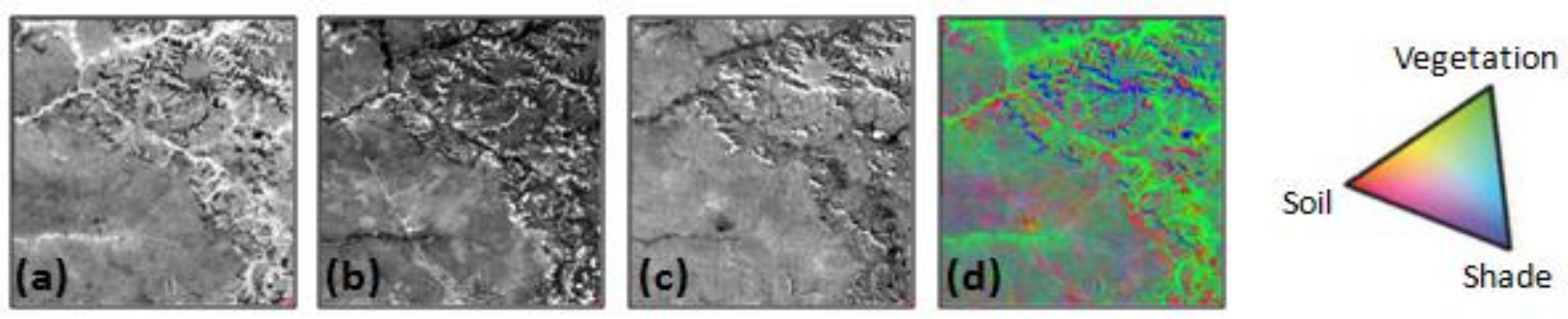

Figure 1. Images resulting from spectral mixing analysis at our research site. Images depict proportions of (a) vegetation, (b) soil and (c) shade, with brighter areas representing higher proportions. A color composite of these fraction images (d), shows the association: vegetation/green, soil/red and shade/blue, demonstrating the spatial distribution of proportions of primary landscape descriptors in Boa Vista (e.g., denser vegetation along streams and variations in soil proportions over the sandy plain, on the lower left corner of the area). The triangle on the right presents potential colors resulting from the combination of the three primary descriptors, with vertices representing pure pixels. Image brightness and contrast were modified to facilitate visualization. Original spatial resolution is $30 \mathrm{~m}$ and images represent an area of 13.5 by $15 \mathrm{~km}$ on the ground. 
elevation, an ASTER DEM (NASA/METI) tile of the study area was geometrically corrected and extracted to observation points. A geometrically and atmospherically corrected Landsat scene of the area of study was used to perform spectral mixing analysis (SMA), generating fraction images representative of the endmembers green vegetation, soil and shade, the latter being a descriptor of soil moisture and vegetation structure, including variations in canopy height, homogeneity and density (Figure 1). The identification of pure pixels required by the spectral mixing analysis followed the methods presented by Small (2004). Pure pixel selection involved cascaded principal component analysis of geometrically and atmospherically corrected images, resulting in the generation of MinimumNoise-Fraction (MNF, Green et al., 1988) images. Pixel Purity Index (PPI, Chaudhry et al., 2006) images were generated and used with MNF results as input to an n-dimensional visualizer, for pure pixel selection. Images representing fractional coverage for vegetation, soil, and shade were generated from a linear spectral mixture model using ENVI image processing software. This procedure resulted in four environmental variable values associated with each observation coordinate: the percent of green vegetation, percent bare soil, percent shade, and elevation.

\subsection{Maximum Entropy Modelling}

MaxEnt software for species habitat modelling, version $3.3 .3 \mathrm{k}$ (from http://www.cs.princeton.edu/ schapire/maxent/), was used to build a model of capuchin monkey habitats for movement. From the 6,793 points of route coordinates collected in the field, all points less than $30 \mathrm{~m}$ apart were removed for model bu ilding, resulting in 862 suitable presence points.
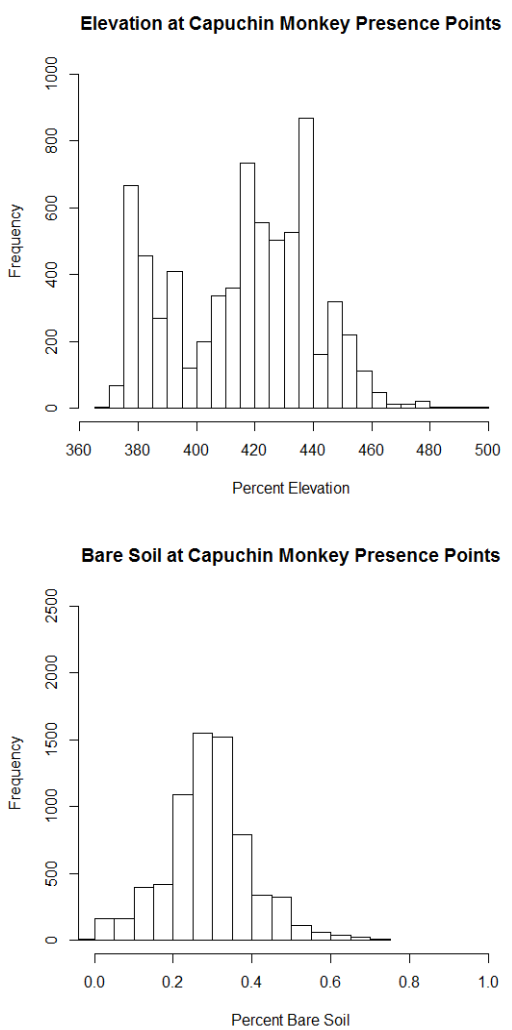

To inform the model of variation in environmental parameters over the area of interest, 10,000 random background points were generated within a 5,000 $\mathrm{m}^{2}$-area around the mean geographic center of all route coordinates. Elevation values as well as fractional image values for green vegetation, soil, and shade were extracted to all background and presence points. The logistic MaxEnt model was created using a 20\% random test percentage of presence points (690 training points, 172 test points). Model results were evaluated using a Receiver Operating Characteristic (ROC) analysis, generating the Area Under the Curve (AUC) measure of model fit where a random model would have an AUC value of 0.5

\section{RESULTS}

Bearded capuchin monkey presence points were clustered around intermediate elevations, with $94 \%$ of presence points being recorded at or below $450 \mathrm{~m}$ elevation. Points varied in their elevation from 369 to $498 \mathrm{~m}(\mathrm{M}=416.3 \mathrm{~m}, \mathrm{SD}=23.8 \mathrm{~m})$. Green vegetation is an important environmental variable for capuchin monkeys as well, with $63 \%$ of capuchin monkey presence points falling between $40 \%$ and $60 \%$ coverage of green vegetation (Figure 2). From the SMA of the landscape's percent coverage of green vegetation, bare soil, and shade, capuchin presence points varied from $98 \%$ to $1 \%$ green vegetation $(\mathrm{M}=48 \%, \mathrm{SD}=12 \%), 70 \%$ to $0 \%$ bare soil $(\mathrm{M}=$ $29 \%, \mathrm{SD}=11 \%)$, and $68 \%$ to $0.1 \%$ shade $(\mathrm{M}=29 \%, \mathrm{SD}=7$ $\%)$.

The geographic distribution of our bearded capuchin MaxEnt movement model is shown in Figure 3. The training AUC value for this model was 0.789 while the test AUC value (i.e., the measure of test data fit to model output) was 0.775 .
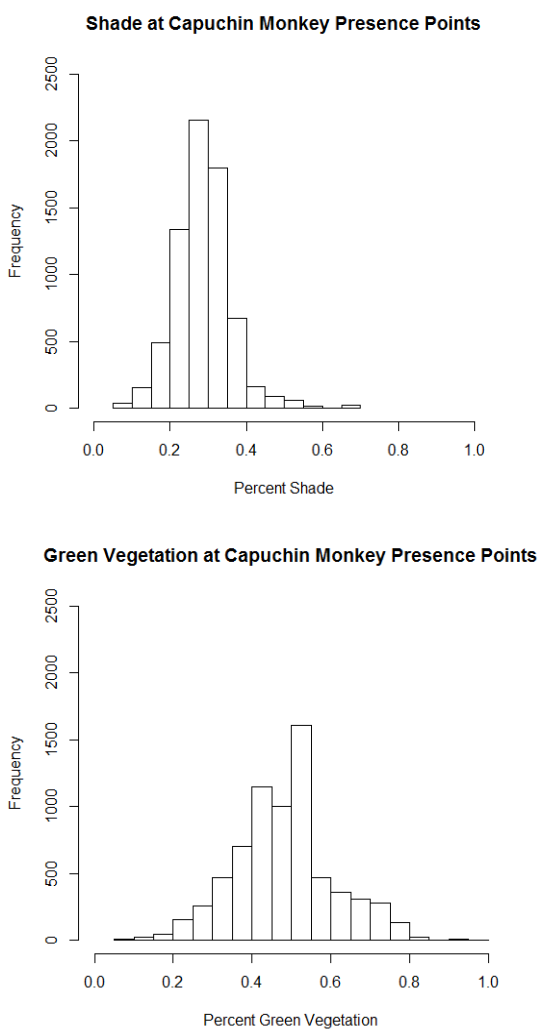

Figure 2. Elevation, percent bare soil, shade, and green vegetation histograms of bearded capuchin monkey presence points. Percents are presented as fractional values 


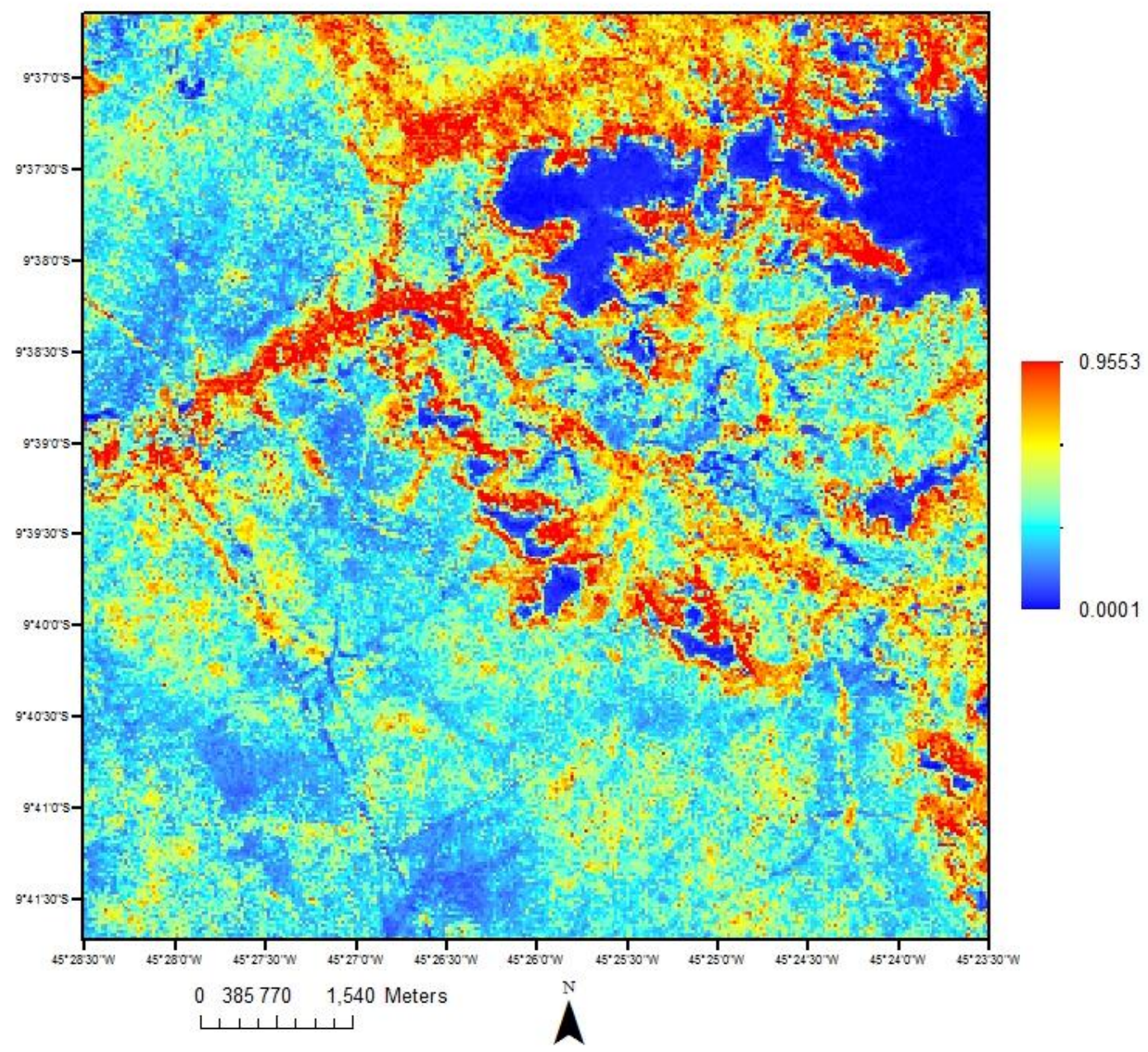

Figure 3. Geographic distribution of the MaxEnt model of bearded capuchin monkey movement. Warmer colors represent habitat predicted by the model to be suitable for capuchin movement while cooler colors represent lower probabilities of habitat suitable for capuchin movement.

An analysis of the relative contributions of individual variables indicated that percent green vegetation was the greatest predictor of capuchin presence points with $45.3 \%$ contribution to the model, followed by percent bare soil $(22.3 \%)$, elevation $(18.4 \%)$, and percent shade (13.9\%). A jackknife test of variable importance (Figure 4) indicated that the variable that decreases model AUC most when omitted is percent green vegetation (veg). Percent green vegetation alone also has the greatest model AUC value when it is the only variable included in the model. Elevation (DEM) contributed the least to model AUC, decreasing AUC the least when it was omitted.

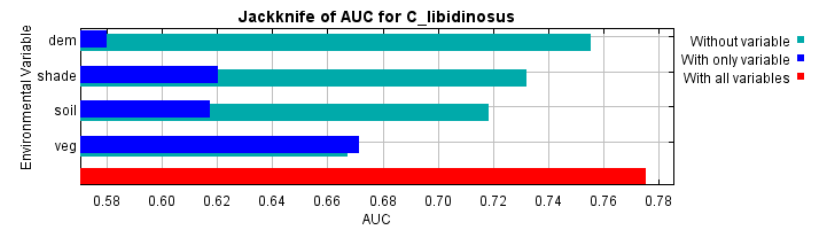

Figure 4. Jackknife plot of variable importance in the MaxEnt model of bearded capuchin movement. Dark blue bars represent the AUC value of the model using only the variable listed to the left. Light blue bars represent the AUC value of the model without the variable of interest. The final red bar shows the AUC of the complete model, including all variables.

\section{DISCUSSION}

Our model suggests that the variables elevation, percent green vegetation, percent bare soil, and percent shade cover all have an impact on the movement patterns of bearded capuchin monkeys at our field site in northeastern Brazil. Capuchin monkeys at our field site appear to prefer to move through areas of low to intermediate elevation. From capuchin monkey presence points, the mean percent coverage of shade and bare soil showed similar values, with each variable representing approximately half the mean percent coverage of green vegetation seen at capuchin monkey presence points. For the monkeys in our study area, daily movements were most likely to occur in areas with nearly $50 \%$ coverage by green vegetation.

Of all environmental layers included in our model, percent green vegetation had the greatest influence on habitat suitable for movement. We attribute the influence of green vegetation on habitat movement suitability to the availability for substrates upon which capuchin monkeys travel. Although bearded capuchins at our field site spend up to $30 \%$ of their time on the ground, they spend the greatest proportion of their time using arboreal substrates (Biondi, 2010). 
In addition, the presence of green vegetation may serve as a vertical substrate on which to evade terrestrial predators (Gursky \& Nekaris, 2007). Green vegetation also serves as a potential location from which to find food resources such as the insects and ground palm nuts upon which bearded capuchin monkeys feed at Boa Vista.

We conclude that MaxEnt species distribution modelling can be used to create a model of habitat appropriate for species movement. The interpretation of this bearded capuchin movement model should be limited to the home range of the two groups from which these movement data were collected. Species presence or absence in other geographic areas, even those nearby our Boa Vista field site, cannot be interpreted using the probabilities from this model. Rather, this model will be used in future applications to interpret the movement decisions of capuchin monkeys and to predict their movement under novel conditions (e.g., habitat change).

\section{REFERENCES}

Biondi, L. 2010. Comportamento posicional e uso de substrato de macacos-prego Cebus libidinosus. (Master Thesis). University of São Paulo, Brazil.

Chaudhry, F., Wu, C., Liu, W., Chang, C., \& Plaza, A. 2006. Pixel purity index-based algorithms for endmember extraction from hyperspectral imagery. Recent advances in hyperspectral signal and image processing. pp. 29-62. Kerala: Transworld Research Network.

Crist, T. O., Guertin, D. S., Wiens, J. A., \& Milne, B. T. 1992. Animal movement in heterogeneous landscapes: An experiment with Eleodes beetles in shortgrass prarie. Functional Ecology, 6, pp. 536-534.

Di Fiore, A. \& Suarez, S. 2007. Route-based travel and shared routes in sympatric spider and woolly monkeys: Cognitive and evolutionary implications. Animal Cognition, 10, pp. 317-329.

Elith, J., \& Leathwick, J. R. 2006. Species Distribution Models: Ecological Explanation and Prediction Across Space and Time. Systematics, pp. 677-697.

Elith, J., Phillips, S. J., Hastie, T., Dudi'k, M., et al. 2009. A statistical explanation of MaxEnt for ecologists. Diversity and Distributions, 17, pp. 43-57.

Elmore, A. J., Mustard, J. F., Manning, S. J., \& Lobell, D. B. 2000. Quantifying vegetation change in semiarid environments : Precision and accuracy of spectral mixture analysis and the Normalized Difference Vegetation Index. Science, 102, pp. 87-102.

Fleishman, E., Nally, R. M., Fay, J. P., \& Murphy, D. D. 2001. Modeling and predicting species occurrence using broadscale environmental variables: An example with butterflies of the Great Basin. Conservation Biology. 15(6), pp. 1674-1685.

Fragaszy, D., Izar, P., Visalberghi, E., Ottoni, E. B., \& de Oliveira, M. G. 2004. Wild capuchin monkeys (Cebus libidinosus) use anvils and stone pounding tools. American journal of primatology, 64(4), pp. 359-66.

Gao, X., Huete, A. R., Ni, W. G., \& Miura, T. 2000. Opticalbiophysical relationships of vegetation spectra without background contamination. Remote Sensing of Environment, 74, pp. 609-620.
Garber, P. A. 1989. Role of spatial memory in primate foraging patterns: Saguinus mystax and Saguinus fuscicollis. American Journal of Primatology, 19(4), pp. 203-216.

Getz, W. M., \& Saltz, D. 52008. A framework for generating and analyzing movement paths on ecological landscapes. Proceedings of the National Academy of Sciences of the United States of America, 105(49), pp. 19066-71.

Green, A. A., Berman, M., Switzer, P., \& Craig, M. D. 1988. A transformation for ordering multispectral data in terms of image quality with implications for noise removal. IEEE Transactions on Geoscience and Remote Sensing, 26, pp. 65-74.

Gursky, S. L., Nekaris, K. A. 2007. Primate Anti-predator Strategies. Springer: New York, pp. 320-321.

Loureiro, F., Rosalino, L. M., Macdonald, D. W., \& SantosReis, M. 2007. Path tortuosity of Eurasian badgers (Meles meles) in a heterogeneous Mediterranean landscape. Ecological Research, 22(5), pp. 837-844.

Phillips, S. J., Anderson, R. P., Schapire, R. E. 2006. Maximum entropy modeling of species geographic distributions. Ecological Modeling, 190, pp. 231-259.

Small, C. 2004. The Landsat ETM+ spectral mixing space. Remote Sensing of Environment, 93, pp. 1-17.

Stickler, C. M. \& Southworth, J. 2008. Application of multiscale spatial and spectral analysis for predicting primate occurrence and habitat associations in Kibale National Park, Uganda. Remote Sensing of Environment, 112, pp. 2170-2186.

Willems, E. P., Barton, R. A., \& Hill, R. A. 2009. Remotely sensed productivity, regional home range selection, and local range use by an omnivorous primate. Behavioral Ecology, 20, pp. 985-992.

Wirsing, A. J., Steury, T. D., \& Murray, D. L. 2002. A demographic analysis of a southern snowshoe hare population in a fragmented habitat: evaluating the refugium model. Canadian Journal of Zoology, 80, pp. 169-177.

\section{ACKNOWLEDGEMENTS}

We acknowledge financial support for this research from a National Science Foundation Planning Grant (739995), the University of Georgia Graduate School, and the UGA Latin American and Caribbean Studies Institute. Infrastructure for research was provided by the Center for Remote Sensing and Mapping Science (CRMS) at the University of Georgia. 